Research/Technical Note

\title{
Logistic Challenges Associated with Supply Chain Management of HIVIAIDS Programs in Cross River State, Nigeria
}

\author{
Samson Olusegun Aturaka ${ }^{1}$, Olaiya Abiodun ${ }^{2}$, Olusola Omotola ${ }^{3}$, Wasiu Olalekan Adebimpe ${ }^{4}$, \\ Philip Imohi ${ }^{5}$, Offiong Okon ${ }^{6}$
}

${ }^{1}$ Department of Health System Strengthening and Laboratory Services, Fhi360 Cross River State Office, Calabar, Nigeria

${ }^{2}$ Department of Health System Strengthening and Logistics, Fhi360/AHNi Benue State Office, Makurdi, Nigeria

${ }^{3}$ Department of Emergency Preparedness Services, Medecins Sans Frontieres French Section, Abuja, Nigeria

${ }^{4}$ Department of Community Medicine, Osun State University, Oshogbo, Nigeria

${ }^{5}$ Department of Prevention, Care and Treatment, Fhi360 Cross River State Office, Calabar, Nigeria

${ }^{6}$ Department of Laboratory Services, General Hospital Ukpem, Calabar, Nigeria

\section{Email address:}

segunhydd@yahoo.com (S. O. Aturaka),drabiodunolaiya@gmail.com (O. Abiodun), dasholi@outlook.com (O. Omotola), olalekanadebimpe@gmail.com (W. O. Adebimpe),phil_imohi@yahoo.com (P. Imohi), ebiekpe@yahoo.com (O. Okon)

\section{To cite this article:}

Samson Olusegun Aturaka, Olaiya Abiodun, Olusola Omotola, Wasiu Olalekan Adebimpe, Philip Imohi, Offiong Okon. Logistic Challenges Associated with Supply Chain Management of HIV/AIDS Programs in Cross River State, Nigeria. American Journal of Health Research. Vol. 5, No. 4, 2017, pp. 114-118. doi: 10.11648/j.ajhr.20170504.15

Received: January 27, 2017; Accepted: May 26, 2017; Published: July 12, 2017

\begin{abstract}
Background: Life-saving drugs such as anti-retroviral therapy and other critical supplies are becoming more accessible to millions of people living with HIV/AIDs. The modern pharmaceutical and laboratory commodity supply and management chain is complex and ravaged with numerous challenges. Objective: of this study is to examine health commodity supply chain management in relation to project implementation of HIV/AIDS and make recommendation for proper management and improvement. Results: ARVs and RTKs formed the basis of most expired commodities encountered. ARVs had $13(23 \%)$ different products of different expiry dates while laboratory reagents had 39 (77\%) products with different expiry dates. Two Sample T-Test and confidence interval for the parameters were carried out and T- calculated for both parameters were found to be less than $\mathrm{T}$ - table. The T- Cal for ARVs were -2.82 while T- Table is 1.71 , also the T-Cal for lab reagents were -3.62 while T-Table was 1.69. This shows that there is no significant difference between the total cost of expired ARVs and expired laboratory reagents since the T-Cal for both products were less than T-Table. Conclusion: Total cost of 51,369.02USD of fund that was lost to expiry was a colossal loss to the project implementation. More funds, time and energy will still be spent on the retrieval, transportation and destruction of these expiries. Activities of different implementing partners (IPs) should be streamlined and rationalized among the IPs to prevent parallel and multiple supply of health commodities to the facilities. Also facility staff should be properly mentored and adequate technical assistance should be rendered to ensure good inventory management and proper storage of all health commodities especially all the cold chain products.
\end{abstract}

Keywords: Commodity Logistics, HIV/AIDs, Supply Chain Management

\section{Introduction}

Life-saving drugs such as anti-retroviral therapy and other critical supplies are becoming more accessible to millions of people living with HIV/AIDs. This has been in part due to the concerted effort of the international community, national governments, private industry, non-governmental organizations and others to improve the availability of supplies. The modern pharmaceutical supply chain is complex, 
as medicines are made from ingredients sourced from different countries and need to be processed and transported down to various importing countries.

Nigeria like most other countries is gradually scaling up access in order to improve coverage. The success of these nationwide programs will depend on the ability of the host country and health systems to reliably and consistently supply the commodities to health facilities at all levels of the health system. Supply chain process is equally challenging most especially in developing countries leading to stock-outs and expired drugs. The deleterious implications of expired and counterfeit drugs is understood to be a central challenge to the integrity of public health systems around the globe, as well as a direct threat to individual health and welfare (Finlay, 2011).

Supplies often get interrupted for many reasons, including intra and inter professional conflicts, industrial strike, poor availability of resources to manage logistics, non-availability of transportation means, lack of technical knowhow on the part of the health care workers, poor donor support among several others. The consequence of supply interruption can be dire, including antibiotic and anti-retroviral drug resistance, which could have a wider global impact on the availability of drugs for treatment.

Several reasons for the complexity of commodity management of HIV/AIDS programs on systemic level are drug resistance; rapidly changing technologies, lack of reliable data on prevalence rates, stigmatization and cultural barriers may impact number of people accessing services, inadequate data from logistics report at the service delivery points, poor attitude of health facility personnel, poor capacity of health staff and frequent Equipment breakdown

Efficient logistics system makes a global economy possible by lowering the cost of living for the people of the world. Information technology has been adopted to support logistics for many years in the name of efficiency. Optimization of information flow to leverage the effectiveness and efficiency of the logistic system wholly is one of the key areas in which the logistic providers are competing with each other. (Hai \& Yirong, 2002).

Ultimately, the goal of every public health logistics system is to help ensure that there is commodity security for every customer and its availability when needed. A proper functioning supply chain system is critical to ensuring commodity security-financing, policies, and commitment are also important. Effective and efficient supply chains system not only help to ensure commodity security or customer satisfaction, it also help determine the success or failure of any public health program.

It is therefore important to evaluate the effects of disruptions on logistic and supply management in order to estimate costs to the health systems and projects. There is poor accountability to the disposal of medicines which complicates the work of the drug regulatory agency, NAFDAC (WHO, 2005) The objective of this study is to examine health commodity supply chain management in relation to project implementation of HIV/AIDS and make recommendation for proper management and improvement.

\section{Methods}

Study Area: The study was conducted in secondary and tertiary health facilities in Cross River state, Nigeria.

Study design: descriptive cross sectional explorative study of logistics systems in selected health facilities. Retrospective facility utilization and supply chain data were examined, and no control group was used.

Inclusion criteria: only health facilities supported by USAID funding were recruited into the study. In addition, only commodities related to HIV programming were examined at facility level to access the effectiveness of the logistics systems used in commodity management.

Research instruments: A checklist was used to collect retrospective data from the pharmacy and laboratory units of selected facilities. Data examined was between the periods of March 2013 to August 2014. Data was counter-verified by the attendant logistics officer on duty at the health facility.

Data analysis: data collected were analyzed using the excel software. Data were presented in form of table and pie charts. Cost estimates were also made for the expired drugs in US dollars to showcase the magnitude of the problem of expired drugs as logistics problems.

Hypothesis

Ho: There is no significant difference in the sample mean

H1: There is significant difference in the sample mean.

\section{Result}

Table 1 showed that the total quantity of ARVs expired $35721(99.4 \%)$ were much more than the expired laboratory products that had only $229(0.6 \%)$ expired products.

Table 2 \& 3 showed Two Sample T- Test at 95\% Confidence Interval unit price and Total unit price per item for Lab Reagents $(-3647,-556)$ and ARVs $(-801,-232)$. The $\mathrm{T}$ Cal were -2.82 and $-3.62, \mathrm{P}$ at 0.0094 and 0.0005 , DF at 24 and 76 . The absolute value of T - Cal $(-2.82,-3.62)<\mathrm{T}-$ Table (1.71, 1.69) shown that there was no significant difference in the sample mean of the two products and null hypothesis was rejected.

Table 1. Quantification of expired commodities supplied to studied facilities.

\begin{tabular}{lll}
\hline Commodities & Quantity (n) & \% \\
\hline ARVs & 35721 & $99.4 \%$ \\
Laboratory & 229 & $0.6 \%$ \\
\hline
\end{tabular}

Table 2. Two Sample T- Test and Confidence Interval@95\% for unit priceVs Total unit price per item (Lab Reagents).

\begin{tabular}{lllll}
\hline $\mathbf{N}$ & $\mathbf{N}$ & Mean & StDev & SE Mean \\
\hline Unit Price & 13 & 2.56 & 2.37 & 0.66 \\
Total Price & 13 & 2109 & 2692 & 747 \\
\hline
\end{tabular}

95\% CI for mu Unit Price - mu Total Price: $(-3647.80,-566)$

T-Test mu Unit Price (vs not $=$ ): $\mathrm{T}=-2.82, \mathrm{P}=0.0094, \mathrm{DF}=24$

Both use Pooled StDev $=1904$

T- Table $=1.71$ 
Table 3. Two Sample T- Test and Confidence Interval @95\% for unit price Vs Total unit price per item (ARVs).

\begin{tabular}{lllll}
\hline $\mathbf{N}$ & $\mathbf{N}$ & Mean & StDev & SE Mean \\
\hline Unit Price & 39 & 151.6 & 90.0 & 14 \\
Total Unit & 39 & 669 & 887 & 142 \\
\hline
\end{tabular}

$95 \%$ CI for mu unit price - mu total un: $(-801,-232)$

T- Test Mu unit price $=$ Mu Total un (vs not $=)$ : $\mathrm{T}=-3.62, \mathrm{P}=0.0005, \mathrm{DF}=76$ Both use Pooled StDev $=631$

T-table $=1.69$

\section{Discussions}

Movement of ARVs and RTKs for example is from the Central Medical Stores down to the health facility and then specifically to the service delivery point at which the customer or user receives and/or uses the products. This followed logistics cycle/steps such as product selection, forecasting and quantification, procurement, warehousing/inventory management and distribution.

The products are numerous with different expiry dates and the work of the logistics officer much more difficult and technical, because he has to take cognizance of each of the expiry dates and take appropriate action to management them in and out of its facility without getting expired and damaged.

Several reasons were given for the inability of the supply system in successful management of ART and laboratory commodities.

(1) Products forecasted on the basis of targets such as prevalence rates will result in over-estimation of commodity requirements and subsequent cases of expiry when consumption is constant.

Multiple venues for distribution of HIV/AIDS programs often use non-traditional distribution sites, taking advantage of market segmentation for product distribution (public sector, social marketing, etc.). Yadav et al in 2012 mentioned that private pharmacies and private wholesalers function well, delivering products to even the most remote areas, if incentives are structured appropriately

(2) Poor Cold or cool chain system: The health commodities that expired within the period of review are ARVs and laboratory reagents in which most of the laboratory reagents are cold chain products. Like other commodities, one of the major problems facing Nigeria's vaccine supply chain is the lack of adequate vaccine storage facilities (Shittu et al., 2016)

(3) Poor inventory management: usually from wrong forecasting and quantification, multiple source of commodities supply. Using first expired first out (FEFO) or other management protocols may not properly work in the absence of proper forecasting,drug selection and storage in the midst of unpredictable consumption by stigma stricken people living with HIV/AIDS (PLWHAs); all leading to expiry of drugs which eventually cost the funders millions of US dollars. Short shelf-life of some HIV/AIDS products such as test kits/reagents and ART drugs, increase the risk of loss due to expiry.

(4) Instability in health sector: Health sector conflicts and industrial strike actions contributes to reasons why health care workers neglect their duty and subsequent drug management systems (Adebimpe and Owolade, 2010). These has led to poor inventory management and create storage issues.

The higher average unit price of antiretroviral (ARVs) compared to that of rapid test kits (RTKs) or other laboratory agents was because ARV has a larger quantity of expiries than laboratory reagents hence the volume of ARVs to be disposed and incinerated is high compare to laboratory reagents. High cost of expired drugs is a waste in the present era of funds dwindling from funders. Implication of these are enormous to the health system coping with the increasing number of PLWHAs and community people being tested and recruited into HIV care in Nigeria, moreover funders are getting more stringent with the available financial and material resources while the host country (Nigeria) is only doing little to complement efforts of IPs and USA ID and other multilateral agencies.

\section{Conclusion}

The expiry of health commodities (ARVs and lab reagents) from March 2013 to August 2014 has a total cost of $51,369.02 \mathrm{USD}$, this is a fund that will be lost to expiries. This is a colossal loss to the project implementation as the fund will have being useful in other thematic areas of the project. However, more funds, time and energy will still be spent on the retrieval, transportation and destruction of these expiries which might also increase the loss of resources significantly. Activities of different IPs should be streamline and rationalized among the IPs to prevent parallel and multiple supply of health commodities to the facilities. This will enhance coordination and effective and judicious use of resources. Proper coordination of distribution, need for monitoring and evaluation team should complement well trained program technical staff to enhance their capacity towards ensuring quality and efficient logistics management of health commodities as well improve expiries management.

The author will like to acknowledge all staff of Central Medical store, Calabar for their support and encouragement 


\section{Appendix}

Table 4. Raw Data of Expired Drugs and Laboratory Reagents.

\begin{tabular}{|c|c|c|c|c|c|c|c|c|}
\hline \#Name? & Item description & Pack size & $\begin{array}{l}\text { FORMULATION (kits, } \\
\text { tabs, granules, solution, } \\
\text { paste, powder) }\end{array}$ & BATCH NO & Quantity & Expiry Date & $\begin{array}{l}\text { Unit Price } \\
\text { (USD)/Pack) }\end{array}$ & $\begin{array}{l}\text { Total Price } \\
\text { (USD)/Item }\end{array}$ \\
\hline & Antiretroval Drugs & & & & & & & \\
\hline 1 & Nevirapine 50mg & $25 \mathrm{ml}$ & oral & G10340 & 257 & Apr-13 & 0.6 & 154.2 \\
\hline 2 & Nevirapine $50 \mathrm{mg} / 5 \mathrm{ml}$ & $25 \mathrm{ml}$ & oral & G10917 & 7300 & Sep-13 & 0.6 & 4380 \\
\hline 3 & Nevirapine $50 \mathrm{mg} / 5 \mathrm{ml}$ & $25 \mathrm{ml}$ & oral & G10929 & 9489 & Sep-13 & 0.6 & 5693.4 \\
\hline 4 & Nevirapine $50 \mathrm{mg} / 5 \mathrm{ml}$ & $25 \mathrm{ml}$ & oral & G10930 & 2280 & Sep-13 & 0.6 & 1368 \\
\hline 5 & Lamivudine $150 \mathrm{mg}$ & 60 & tabs & LV1511048A & 56 & Nov-13 & 2.33 & 130.48 \\
\hline 6 & Nevirapine 50mg & 30 & tabs & NB5011011-A & 425 & Nov-13 & 0.6 & 255 \\
\hline 7 & Nevirapine $50 \mathrm{mg} / 5 \mathrm{ml}$ & $25 \mathrm{ml}$ & oral & СР2011 & 14906 & Dec-13 & 0.6 & 8943.6 \\
\hline 8 & Zidovudine $300 \mathrm{mg}$ & 60 & tabs & X10490 & 22 & Feb-14 & 8.2 & 180.4 \\
\hline 9 & Stav/Lam 6/30mg & 60 & tabs & G24645 & 20 & May-14 & 1.9 & 38 \\
\hline 10 & $\mathrm{Stav} / \mathrm{Lam} / \mathrm{Nev} 6 / 30 / 50 \mathrm{mg}$ & 60 & tabs & G27296 & 177 & May-14 & 4.3 & 761.1 \\
\hline 11 & $\mathrm{Stav} / \mathrm{Lam} / \mathrm{Nev} 6 / 30 / 50 \mathrm{mg}$ & 60 & tabs & G27782 & 295 & Jul-14 & 4.3 & 1268.5 \\
\hline \multirow[t]{3}{*}{12} & $\mathrm{Stav} / \mathrm{Lam} / \mathrm{Nev} 6 / 30 / 50 \mathrm{mg}$ & 60 & tabs & G27709 & 494 & Aug-14 & 4.3 & 2124.2 \\
\hline & Total & & & & Oct-97 & & 28.93 & 25296.88 \\
\hline & Lab reagents and consumables & & & & & & & \\
\hline 1 & Ise Diluent & $1 \mathrm{X} 12 \mathrm{ml}$ & Solution & $11-2899$ & 4 & Jan-13 & 233.33 & 933.32 \\
\hline 2 & Ise Diluent & $1 \mathrm{X} 12 \mathrm{ml}$ & Solution & $12-0620$ & 3 & Apr-13 & 233.33 & 699.99 \\
\hline 3 & Elitrol 1 & $1 \mathrm{X} 12 \mathrm{ml}$ & Solution & 11-0641 & 6 & Oct-12 & 198.67 & 1192.02 \\
\hline 4 & $\mathrm{ALT} / \mathrm{GPT}$ & $9 \times 50 \mathrm{ml}$ & Solution & $11-1115$ & 1 & Dec-12 & 69.05 & 69.05 \\
\hline 5 & $\mathrm{ALT} / \mathrm{GPT}$ & $9 \times 50 \mathrm{ml}$ & Solution & $12-0745$ & 7 & Oct-13 & 69.05 & 483.35 \\
\hline 6 & Glucose STD & $1 \mathrm{X} 12$ & Solution & $12-0201$ & 2 & Dec-12 & 39.72 & 79.44 \\
\hline 7 & FACSC Control & pck & Solution & 11-0781 & 2 & Dec-12 & 300 & 600 \\
\hline 8 & AST/GOT & $9 \times 50 \mathrm{ml}$ & Solution & $11-0764$ & 1 & Dec-12 & 75.75 & 75.75 \\
\hline 9 & AST/GOT & $9 \times 50 \mathrm{ml}$ & Solution & $12-0225$ & 3 & Sep-13 & 75.75 & 227.25 \\
\hline 10 & Creatinine Jaffe & $4 X 250 \mathrm{ml}$ & Solution & $11-0781$ & 6 & Dec-12 & 64.35 & 386.1 \\
\hline 11 & Eight Check Control & $12 \mathrm{X} 1.5 \mathrm{ml}$ & Solution & $12-0745$ & 3 & Sep-13 & 250 & 750 \\
\hline 13 & Elical 2 & $1 \mathrm{X} 12 \mathrm{ml}$ & Solution & $11-0764$ & 2 & Sep-13 & 39.72 & 79.44 \\
\hline 14 & Ise Calibrator High & $1 \mathrm{X} 12 \mathrm{ml}$ & Solution & $12-0201$ & 2 & Dec-13 & 250 & 500 \\
\hline 15 & Ise Calibrator Low & $1 \mathrm{X} 12 \mathrm{ml}$ & Solution & 11-0781 & 2 & Oct-13 & 250 & 500 \\
\hline 16 & Ise Conditioner & $1 \mathrm{X} 12 \mathrm{ml}$ & Solution & $12-0225$ & 2 & Dec-13 & 187.5 & 375 \\
\hline 17 & Ise Cleaner & $1 \mathrm{X} 12 \mathrm{ml}$ & Solution & $12-0745$ & 2 & Nov-13 & 187.5 & 375 \\
\hline 18 & Acid Solution & $40 \mathrm{ml}$ & Solution & $11-0764$ & 3 & Sep-13 & 174.67 & 524.01 \\
\hline 19 & Electrol 2 & $10 \times 5 \mathrm{ml}$ & Solution & $12-0201$ & 2 & Dec-12 & 326 & 652 \\
\hline 20 & Glucose PAP & $4 \times 250 \mathrm{ml}$ & Solution & $12-0747$ & 5 & Jul-13 & 51.68 & 258.4 \\
\hline 21 & Glucose PAP & $4 \mathrm{X} 250 \mathrm{ml}$ & Solution & 11-0781 & 2 & Sep-13 & 51.68 & 103.36 \\
\hline 22 & Glucose PAP & $4 \mathrm{X} 250 \mathrm{ml}$ & Solution & A110800 & 2 & Oct-13 & 51.68 & 103.36 \\
\hline 23 & Stromatolyzer & $500 \mathrm{ml}$ & Solution & D2017 & 1 & Jun-13 & 324.03 & 324.03 \\
\hline 24 & Cell Clean & $50 \mathrm{ml}$ & Solution & A2011 & 2 & Apr-13 & 127.61 & 255.22 \\
\hline 25 & Potasium & $90 \mathrm{ml}$ & Solution & 4900112 & 3 & Jan-14 & 62.05 & 186.15 \\
\hline 26 & Reflotron Potasium & $1 \times 15$ & Strip & $212052-03$ & 30 & Jul-13 & 92.48 & 2774.4 \\
\hline 27 & Reflotron Glucose & $1 \times 15 \mathrm{ml}$ & Strip & $218077-02$ & 13 & Sep-13 & 68.38 & 888.94 \\
\hline 28 & Reflotron Potasium & $1 \times 15 \mathrm{ml}$ & Strip & 214 179-03 & 8 & Sep-13 & 92.48 & 739.84 \\
\hline 29 & Reflotron Urea & $1 \times 15 \mathrm{ml}$ & Strip & $218356-02$ & 55 & Sep-13 & 90.18 & 4959.9 \\
\hline 30 & Reflotron GPT & $1 \times 15 \mathrm{ml}$ & Strip & $216102-01$ & 15 & Dec-13 & 92.48 & 1387.2 \\
\hline 31 & Reflotron BILI & $1 \times 15 \mathrm{ml}$ & Strip & 219261-02 & 20 & Dec-13 & 89.48 & 1789.6 \\
\hline 32 & Reflotron Creatinine & $1 \times 15 \mathrm{ml}$ & Strip & $214179-03$ & 2 & Sep-13 & 87.18 & 174.36 \\
\hline 33 & Reflotron GOT & $1 \times 15 \mathrm{ml}$ & Strip & $218073-04$ & 3 & Dec-13 & 92.48 & 277.44 \\
\hline 34 & Sheath Fluid & 1x5lit & Solution & 120601 & 2 & Aug-13 & 269.46 & 538.92 \\
\hline 35 & Sheath Fluid & 1x5lit & Solution & 116227 & 1 & Nov-13 & 269.46 & 269.46 \\
\hline 36 & Sheath Fluid & 1x5lit & Solution & 120529 & 5 & Jul-13 & 269.46 & 1347.3 \\
\hline 37 & Decontamination Solution & $1 \mathrm{xz} 250 \mathrm{ml}$ & Solution & 1131500009 & 2 & Dec-13 & 162.67 & 325.34 \\
\hline 38 & Triglycerides & $9 \times 50 \mathrm{ml}$ & Solution & $12-0225$ & 2 & Sep-13 & 127.6 & 255.2 \\
\hline 39 & coulter AC 5diff Control plus & $2 \times 2.3 \mathrm{ml}$ & Solution & 0913 & 1 & Nov-13 & 216 & 216 \\
\hline \multirow[t]{3}{*}{40} & Count check Beads & $25 \mathrm{ml}$ & Solution & KW120726 & 2 & Sep-13 & 198 & 396 \\
\hline & & & & & 229 & & 5910.91 & 26072.14 \\
\hline & Grand Total & & & & & & 5939.84 & 51369.02 \\
\hline
\end{tabular}




\section{References}

[1] Adebimpe W. O, Owolade O. O and Adebimpe M. A (2012). Health worker's perception of the use of strikes as a tool for dispute resolution in Lagos state Nigeria. Journal of Social science and public policy, $2: 19 ; 26$.

[2] Finlay BD (2011). Counterfeit drugs and national security [Online]. Available at:

http://www.stimson.org/images/uploads/research-pdfs/Full Counterfeit_Drugs_and_National_Security.pdf. Accessed 11th November $\mathbf{2} 015$.

[3] Hai Lu \& Yirong Su, (2002), An Approach Towards Overall Supply Chain Efficiency - A Future Oriented Solution and Analysis in Inbound Process, Master's Thesis No. 2002: 29, Goteborg: Goteborg University.

[4] http://logisticsmanagementandsupplychainmanagement.wordp ress.com/category/healthcare-logistics/ (Assessed, 11th February, 2013).

[5] Langer E, Kelkar A (2013). Pharmaceutical distribution in India. BioPharm International. 200821 (10) Available at http://www.biopharminternational.com/biopharm/India+Today /Pharmaceutical-Distribution-in-India/ArticleStandard/Article/ detail/557245. Accessed 11th November 2015.
[6] Logistics Systems: Arlington, Va.: John Snow, Inc./DELIVER for USAID for the U.S. Agency for Interna $\neg$ tional Development. Available on: http://pdf.usaid.gov/pdf_docs/PNADM531.pdf (Accessed 6th May, 2012).

[7] Shittu E, Harnly M, Whitaker S, Miller R (2016). Reorganizing nigeria's vaccine supply chain reduces need for additional storage facilities, but more storage is required. Health, Aff (Millwood), 35 (2): 293-300.

[8] USAID/DELIVER PROJECT, Task Order 1. 2011. The Logistics Handbook: A Practical Guide for the Supply Chain Management of Health Commodities. Arlington, Va.: USAID / DELIVER PROJECT, Task Order 1.

[9] World Health Organisation (WHO) (2005). Combating counterfeit drugs: A concept paper for effective international cooperation [Online]. Available at:http://www.who.int/medicines/services/counterfeit/Combati ngCounterfeitDrugs_Conceptpaper.pdf. Accessed 11th November 2015.

[10] Yadav P, Smith R, Hanson K (2012). Pharmaceuticals and the health sector. In: Smtih R, Hanson K, editors. In Health systems in low- and middle-income countries: An economic and policy perspective. Oxford, NY: Oxford University Press; 2012. 